\title{
Assessing the Reality of a Palaeolithic "Dwelling Structure" in the Japanese Archipelago: The Structure of the Tana-Mukaihara Site
}

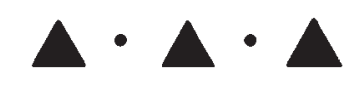

\author{
TAKANORI SAKASHITA
}

\section{INTRODUCTION}

JAPANESE PALAEOLITHIC ARCHAEOLOGISTS have long presupposed that the scarcity of dwelling structures found in Upper Palaeolithic sites of the Japanese Islands was due to ephemeral site occupations. In fact, Japanese Palaeolithic sites have seldom yielded features such as elaborated hearths and pits, as opposed to the common discovery of scatters of lithic artifacts, pebbles, and charcoal fragments (e.g., Akazawa et al. 1980:136-225; Imamura 1996:19-38; Mizoguchi 2002:49-74; Yajima 2004).

The Tana-Mukaihara site in the southern Kanto Plain, Honshu, has been regarded as a credible Upper Palaeolithic site with a dwelling structure. The municipal government registered the site as a national historic site in 1999, and it is now preserved as a historic-site park. Although Japanese researchers have attempted to designate some credible dwellings among numerous Japanese Upper Palaeolithic sites (Aita 1992; C. Suzuki 1983), critical revaluations (e.g., Inada 2004; Kurishima 1989) suggest that only a few sites possess reliability in their identification as dwelling structures. The goal of this article is to discuss the assumption of Upper Palaeolithic settlements with clear habitation structures through a critical evaluation of the validity of the "dwelling structure" at the Tana-Mukaihara site.

\section{THE TANA-MUKAIHARA SITE}

Archaeological work at the Tana-Mukaihara site, located in Sagamihara City in Kanagawa Prefecture (Fig. 1), has yielded a series of recently published monographs reporting on four sets of excavations (The Educational Board of Sagamihara City 2003, 2004, 2006). This article concentrates on the materials, including artifacts and the dwelling structure, found in the first and second excavations, because the archaeological remains recovered in the third and fourth excavations were recovered far outside the major excavation area where the dwelling structure was identified (Fig. 1).

The first excavation was conducted by the Excavation Group of Tana-Shioda sites during the period from February 20 to August 2, 1997. It is in this excavation 


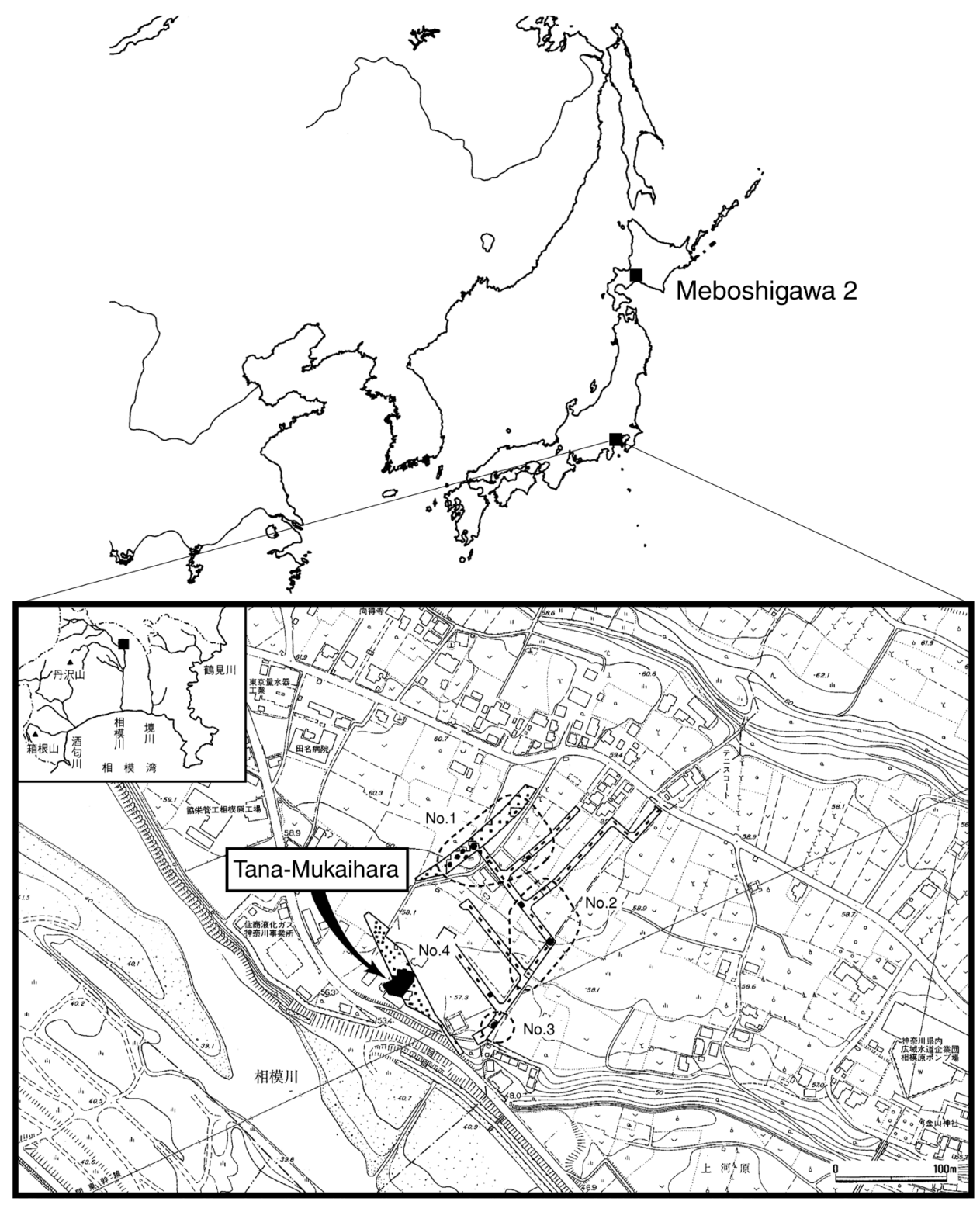

Fig. 1. Location map of the Tana-Mukaihara site (The Tana-Shioda Sites Excavation Group 1998, Fig. 1, partly modified).

campaign that lithic scatters and two pebble clusters, a dwelling structure primarily identified as a pebble-surrounded habitation, as well as what were identified as twelve postholes and two hearths, were found. The second excavation campaign, conducted between July 30 and August 27, 2001, was aimed at obtaining additional data regarding the nature of the dwelling structure for the purpose of preservation, a requisite procedure of national registration. Only the southeastern quadrant of the structure was re-excavated. Below, I summarize the results of the two excavation campaigns 
that were officially reported by the research committee of the Tana-Mukaihara Site (organized after the execution of first excavation campaign) affiliated with the Educational Board of Sagamihara City.

\section{Chronology}

Cultural chronologies of the Upper Palaeolithic have been developed by taking advantage of layers of thick loam (including eolian dust or loess from China) with volcanic ash that are well stratified in regions of the Japanese Islands. The central part of the country particularly offers secure chronologies of lithic industries using stratigraphic and morpho-typological studies: 1) trapezoid industries which appeared across the Japanese Islands; 2) backed-knife industries common during the early to late phases of the Upper Palaeolithic; 3) point-tool industries concentrated in central Japan; and 4) microblade industries found all over the islands by the onset of the Incipient Jomon industries (Ono et al. 2002).

The study site of Tana-Mukaihara is located on the left bank of the Sagami River on the Sagamino Upland in the southern Kanto Plain, Honshu. In terms of characteristics of the lithic assemblage, it belongs to the point-tools industry. The AMS ${ }^{14} \mathrm{C}$ dates obtained from the charcoal specimens collected from the surface level of the postholes (P9, P10) are centered around c. 17,600 B.P.: 17,650 \pm 60 [Beta-127792] and $17,630 \pm 50$ [Beta-127793] R.C.Y. B.P. (estimated around 19,000 to 23,000 CAL.Y.B.P.) (Tsuji et al. 2004).

\section{Artifacts}

Excluding manuports from the pebble-surrounded structure and the pebble clusters, the total number of lithic artifacts is 3450. In addition, 2981 lithic artifacts were found from the "habitation area" of the site (Table 1). The chipped stone artifacts of the Tana-Mukaihara site are characterized by bifacial points and abundant use of obsidian (Fig. 2). Unlike the unusual discovery of the dwelling structure, techno-typological characteristics of the lithic assemblage are pan-regional: the bifacial points are one

Table i. Artifact Assemblage from the Tana-Mukaihara Site

\begin{tabular}{|c|c|c|c|c|c|c|c|c|c|}
\hline & & BACKED & & SCALE & & & & & \\
\hline & POINTS & KNIVES & SCRAPERS & PIECES & BURINS & FLAKES & CORES & PEBBLES & TOTAL \\
\hline \multicolumn{10}{|c|}{ Dwelling structure } \\
\hline Obsidian & 171 & 16 & 31 & 9 & 2 & 2114 & 14 & - & 2357 \\
\hline Others & 22 & 5 & 23 & - & 1 & 555 & 13 & 5 & 624 \\
\hline \multicolumn{10}{|c|}{ Lithic scatter 1} \\
\hline Obsidian & 10 & - & 2 & - & - & 78 & - & - & 90 \\
\hline Others & 20 & 2 & 4 & - & 2 & 197 & 4 & 20 & 249 \\
\hline \multicolumn{10}{|c|}{ Lithic scatter 2} \\
\hline Obsidian & 1 & - & - & - & - & 1 & - & - & 2 \\
\hline Others & 13 & 1 & 1 & - & - & 78 & 3 & 6 & 102 \\
\hline \multicolumn{10}{|l|}{ Others } \\
\hline Obsidian & 3 & - & 2 & - & - & 2 & - & - & 7 \\
\hline Others & - & - & - & - & - & 7 & 1 & 11 & 19 \\
\hline Total & 240 & 24 & 63 & 9 & 5 & 3032 & 35 & 42 & 3450 \\
\hline
\end{tabular}



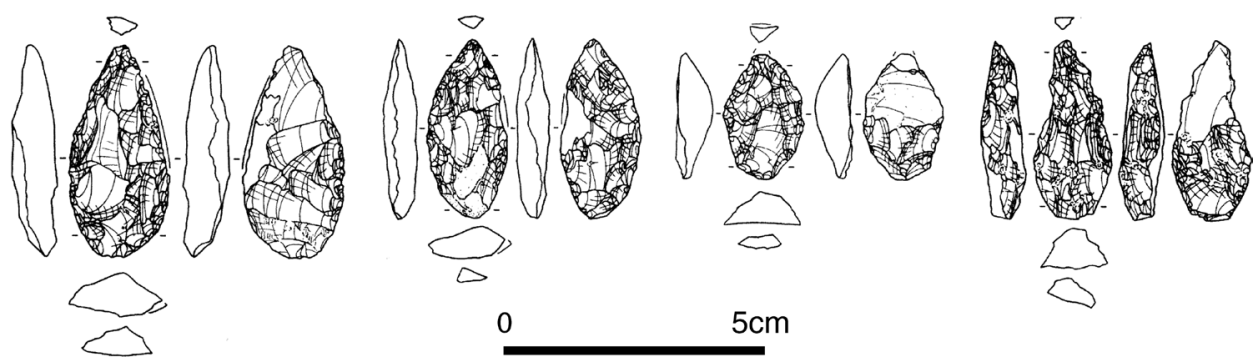

Fig. 2. Obsidian bifacial points in the Tana-Mukaihara site (The Tana-Shioda Sites Excavation Group 1998, Fig. 8, partly modified).

of the prominent tool classes found around the Upper Palaeolithic assemblages of southern Kanto and central Honshu (Shiraishi 2004).

\section{Features}

Below is a summary of identified characteristics of the dwelling structure completed by initial examinations of official site reports. Three remarkable features-postholes, hearths, and a pebble-surrounded structure-were distinguished (Ono 2004) (Fig. 3).

1. Postholes: A total of 12 postholes were identified. In the first excavation, postholes $\mathrm{P} 2$ and $\mathrm{P} 4$ from the west side, and P8, P9, and P10 from the east side were found. It is reasonable to suppose that the entrance was between postholes P1 and P10 where pebbles are less visible.

2. Hearths: The hearth F2 is located slightly eastward from the center of the dwelling structure and the sediments sampled from Hearth F2 recorded a paleo-magnetic signature of burning.

3. Pebble-surrounded structure: The pebble-surrounded structure is comprised of circularly arranged pebbles of porous andesite. No artifacts (i.e., lithic artifacts including macrodebitage and charcoal fragments) are identified outside this circularly arranged pebble cluster, and therefore the pebbles played a role in limiting the spatial boundary of the presumed residential area, our dwelling structure.

\section{Issues with the Evidence}

On the occasion of observing the artifacts from Tana-Mukaihara, I noticed possible burning evidence on some obsidian flakes from the study site assemblage, which exhibited a lusterless appearance. Similar observations were noted in the first report (Aso $2003: 20)$, although no further systematic study of these possible burned areas had been conducted.

Given the presence of two hearths near the dwelling structure, it is quite possible that a proportion of artifacts were subjected to heat, more than the small number of artifacts that were judged to be thermally altered by the unaided eye. The present study examines thermal alteration of obsidian from the study assemblage of TanaMukaihara to evaluate the interpretations of the site structure, particularly the validity of the dwelling structure (Sakashita 2007, 2008). 


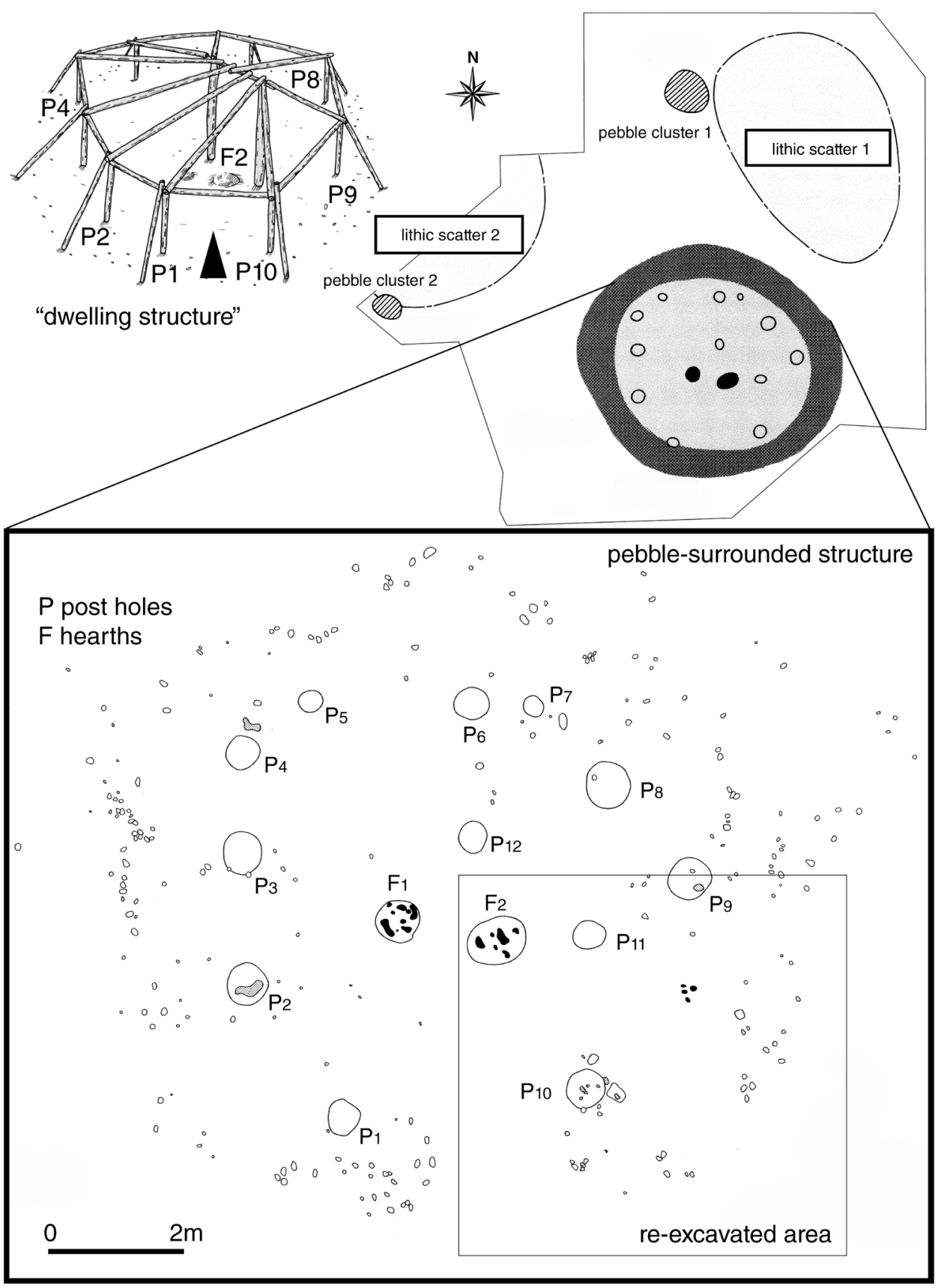

Fig. 3. Plan of archaeological features in the Tana-Mukaihara site (The Tana-Shioda Sites Excavation Group 1998, Figs. 3-5, partly modified). 


\section{METHODS}

Since the 1970s, researchers have recognized obsidian artifacts that do not retain glassy luster among artifacts recovered from Upper Palaeolithic sites in Hokkaido, and obsidian artifacts without a shiny appearance have been designated as thermally altered (Kato 1970; Kato et al. 1970). The loss of a lustrous appearance on obsidian flakes is due to adherence of heated wood ash, which was first identified by experiments that were designed to reveal the loss of fission tracks in obsidian (Fukuoka and Koshimizu 1990; Koshimizu and Fukuoka 1991). Similar experiments have further discovered that the thermally altered surface was composed of tiny cracks detected through microscopic observations, and tiny cracks were observed on the obsidian artifacts from the late Upper Palaeolithic of the Meboshigawa 2 site (c. 17,000-10,000 B.P.), Hokkaido, Japan (Nakazawa 2000) (see Figure 1). In this article, to confirm the reliability of criteria in the identification of thermally altered obsidian, I report on my replicated experiments of work that was originally done by Nakazawa (2000).

\section{Thermal Alteration on Obsidian}

There are six morphological patterns identified as possible traits of thermal alteration on obsidian: (1a) curved crazing, (1b) squamoid crazing, (1c) tiny cracks, (2) vesiculation, (3a) breakage with a flat surface, and (3b) breakage with an irregular surface. All of these patterns are easily distinguished with the unaided eye, except Type 1c; their tiny cracks are often detectable under the microscope. In the previous study of the Meboshigawa 2 assemblage, a total of 4963 obsidian artifacts were observed under the microscope at the magnification of 15 to 50 power and Nakazawa identified the frequencies of all possible thermal traits (Nakazawa 2000). Since in some cases, multiple patterns of thermal alteration are found on a specimen, the total number of occurrences in the types exceeds the total number of artifacts $(n=4963)$. In his analysis, Nakazawa provided both the total observations in each category and the percentages of the occurrences of the traits on the artifacts relative to the total number of artifacts: (1a) 1507 with curved crazing (67\%); (1b) 108 with squamoid crazing (5\%); (1c) 1000 with tiny cracks (44\%); (2) 87 with vesiculation (4\%); (3a) 162 with breakage on a flat surface (7\%); and (3b) 79 with breakage on an irregular surface (4\%).

\section{Tiny Cracks}

The tiny cracks (1c) are the only trait of thermal alteration that is experimentally replicated. They are generated on the surface of obsidian when covered with heated wood ash. The laboratory-controlled experiments that used obsidian from the provenance of Oketo in eastern Hokkaido show that certain ranges of temperature and duration of heating (at least 9 hours in $550^{\circ} \mathrm{C}$ ) affected the occurrence of tiny cracks (Nakazawa 2000, 2002).

Since the types of alteration other than tiny cracks were not replicated in the experiments, they are not used as criteria for identification of thermal alteration on obsidian. The underlying factors that caused variability in traits of thermal alteration would be more complex than the experimental conditions could replicate. It is an interesting research avenue to elucidate how various types of thermal traits are generated under different conditions of heat. 


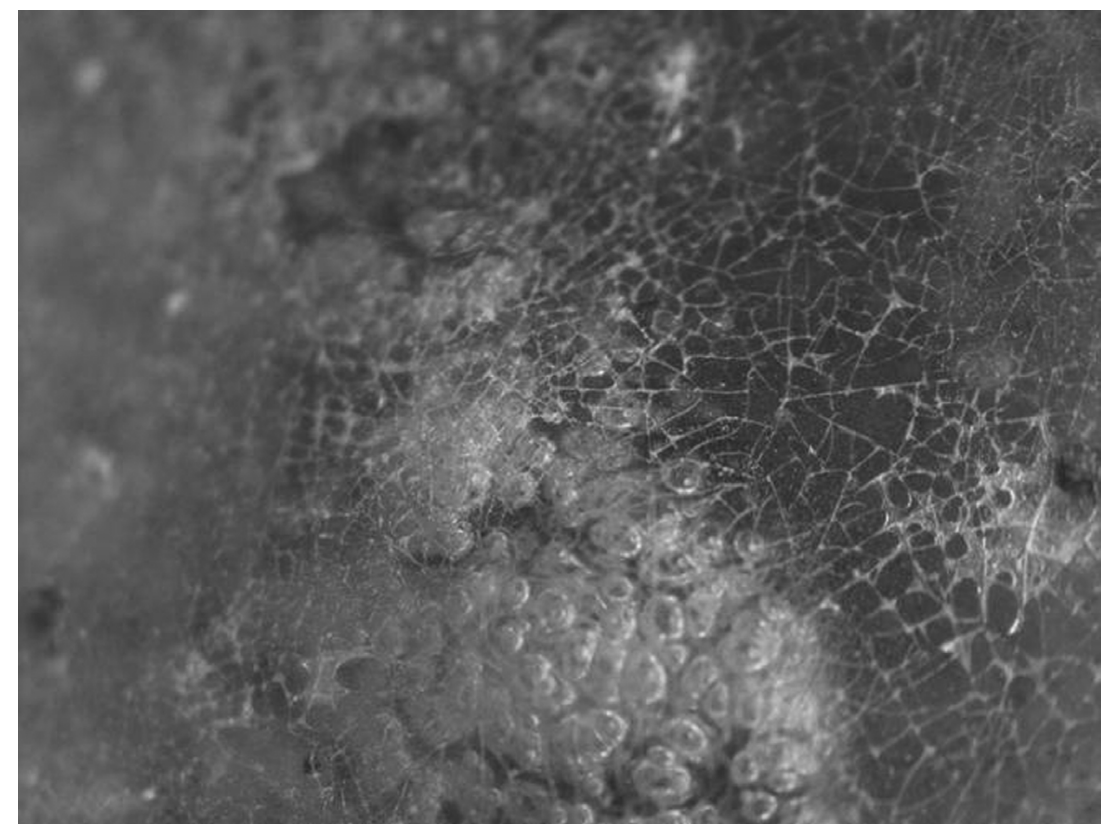

Fig. 4. Artifacts of the thermally altered obsidian (60x) (Sakashita 2008: Fig. 4).

Table 2. Counts and Ratio of the Thermally Altered Obsidian Artifacts

\begin{tabular}{lcccc}
\hline & $\begin{array}{c}\text { NON-THERMALly } \\
\text { Altered }\end{array}$ & $\%$ & $\begin{array}{c}\text { THERMALly } \\
\text { Altered }\end{array}$ & $\%$ \\
\hline Chips & 764 & 95.9 & 33 & 4.1 \\
Flakes & 1254 & 95.2 & 63 & 4.8 \\
Retouched tools & 237 & 97.5 & 6 & 2.5 \\
Total & 2255 & 95.7 & 102 & 4.3 \\
\hline
\end{tabular}

\section{RESULTS}

\section{Observations of Obsidian Artifacts Using a Stereoscopic Microscope}

Examination of the 2456 obsidian artifacts recovered from the first excavation campaign of the Tana-Mukaihara site was conducted by stereoscopic microscope at the magnifications of 15 to 60 power. As summarized below, the frequencies of thermal traits are different from those of the obsidian specimens from the Late Upper Palaeolithic assemblage of Meboshigawa 2. Neither curved crazing (1a) nor squamoid crazing (1b) were identified, while vesiculation (2), breakage with flat surface (3a), and breakage with irregular surface (3b) were found in combination with tiny cracks (1c) (see Figure 4). Only one specimen is completely vesiculated.

Based on the laboratory experiments, I identified thermal alteration on a total of 102 obsidian specimens with tiny cracks (Table 2), constituting 99\% of the obsidian in the sample. Only 2 of the pieces had vesiculation (2\%); 34 pieces showed breakage with a flat surface (34\%); and only 1 piece manifested breakage with an irregular 


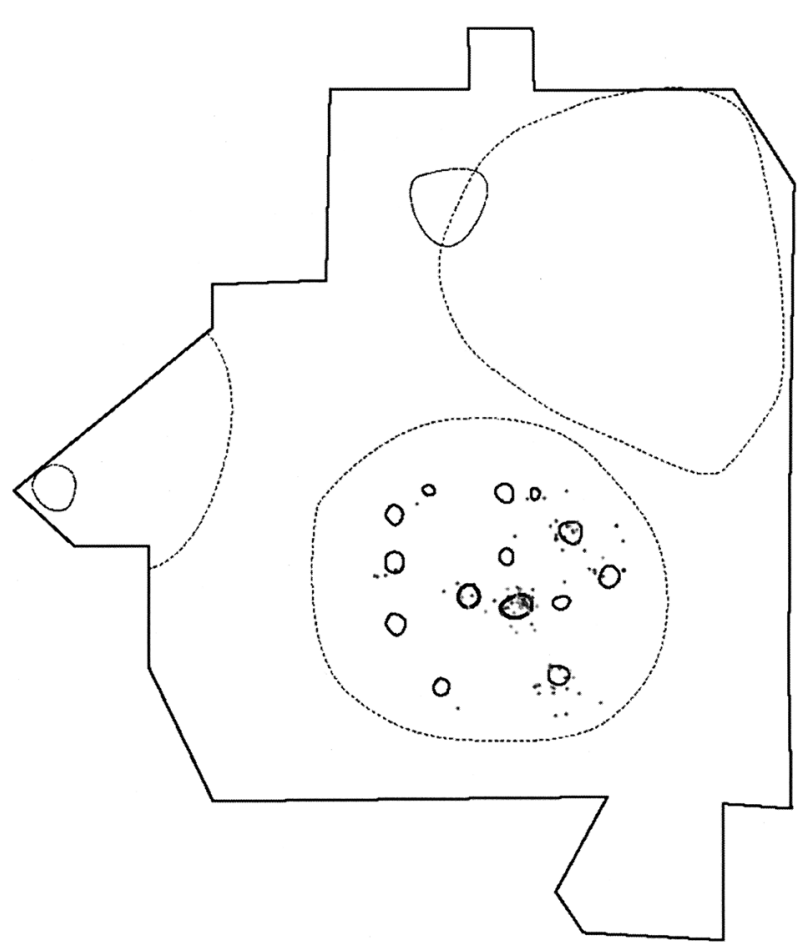

Fig. 5. Distribution of the thermally altered obsidian artifacts (Sakashita 2008: Fig. 5).

surface $(1 \%)$. In addition, the results of obsidian sourcing for the artifacts from the Tana-Mukaihara site showed that recovered obsidian were mostly obtained from the neighboring sources close to the southern Kanto region, although no thermally altered obsidian artifacts have been provided for sourcing analysis.

\section{The Spatial Distribution of Thermally Altered Obsidian Artifacts}

Locating the identified thermally altered obsidian artifacts within artifact distribution maps reveals a peculiar pattern. They are distributed exclusively within the pebblesurrounded structure and not located within the two lithic scatters and pebble clusters (Fig. 5). While thermally altered obsidian artifacts are distributed across the area inside the pebble-surrounded structure, it seems that they are concentrated in and around hearth F2, and postholes P8 and P10.

Since the thermally altered obsidian artifacts are distributed in a limited area, I further examined whether the macrodebitage (small chips longer than $1 \mathrm{~mm}$ ) collected by Sachiko Okazawa during the second excavation (Okazawa 2004) are thermally altered or not. It is legitimate to assume that grain-sized artifacts (i.e., macrodebitage) are less susceptible to displacement than larger artifacts (e.g., Binford 1978; Bowers et al. 1983; Metcalfe and Heath 1990; O'Connell 1987). Thus, the formation processes of the pebble structures are reasonably evaluated by the examination of obsidian debitage.

Observations of all of the macrodebitage collected from the sampled section using the digital microscope (Keyence VHX-100) at a magnification of 25 to 75 power show that tiny cracks identified by the stereoscopic microscope were also found on these specimens (Fig. 6). The thermally altered macrodebitage is not only concen- 


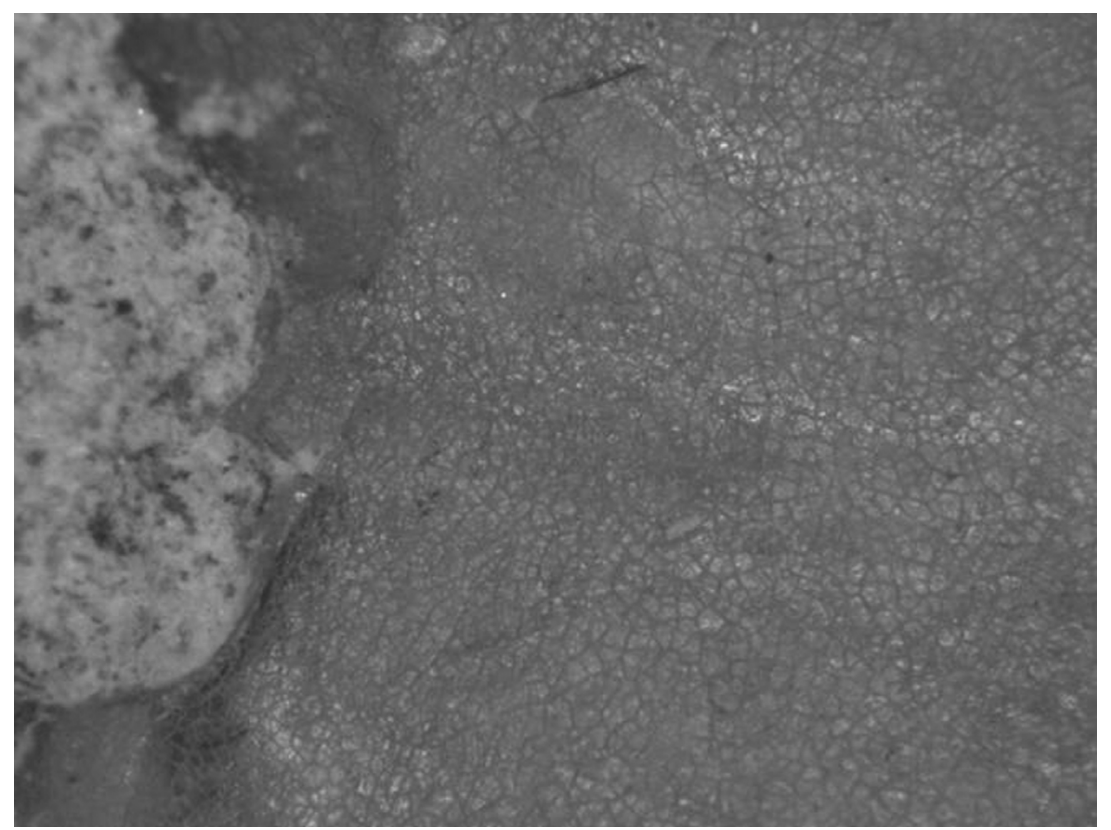

Fig. 6. The thermally altered obsidian macrodebitage (75x) (Sakashita 2008: Fig. 8).

trated in the hearth F2 and posthole P10, which are identical to that of the manually collected samples in the first excavation, but they are also found on the southern side of posthole P9 (Fig. 7).

\section{DISCUSSION}

\section{On the Morphological Variation in Thermal Traits of Obsidian}

The variability in thermal alteration of obsidian artifacts from the Tana-Mukaihara assemblage (southern Kanto) is different from that of the Meboshigawa assemblage (Hokkaido). Thermally altered obsidian artifacts of the Tana-Mukaihara assemblage have the following characteristics: (1) the amount of thermally altered artifacts is small; and (2) neither curved crazing (Nakazawa's type 1a) nor squamoid crazing (Nakazawa's type $1 \mathrm{~b}$ ) are present. Based on my empirical observations of obsidian artifacts from the assemblages of Hokkaido, all traits of thermal alteration are abundantly present on the specimens. This tendency toward partial observations of the sites is probably substantial because of the difference in research history: thermal alteration of obsidian has been well described in the assemblages of Hokkaido since the 1970s, while thermal alteration in chipped stone assemblages in the southern Kanto region has garnered little attention. These suggest that the reason why the morphological variability in thermal alteration of obsidian in Hokkaido assemblages is higher than that of the southern Kanto may be because artifacts buried in the semi-arctic environment of Hokkaido underwent various freeze-thaw processes, which in turn created variable morphologies of thermal traits such as curved crazing (1a) and squamoid crazing (1b). In contrast, a behaviorally based theory would view these differences in proportions of thermally altered artifacts among the different regions (in this case, between southern 


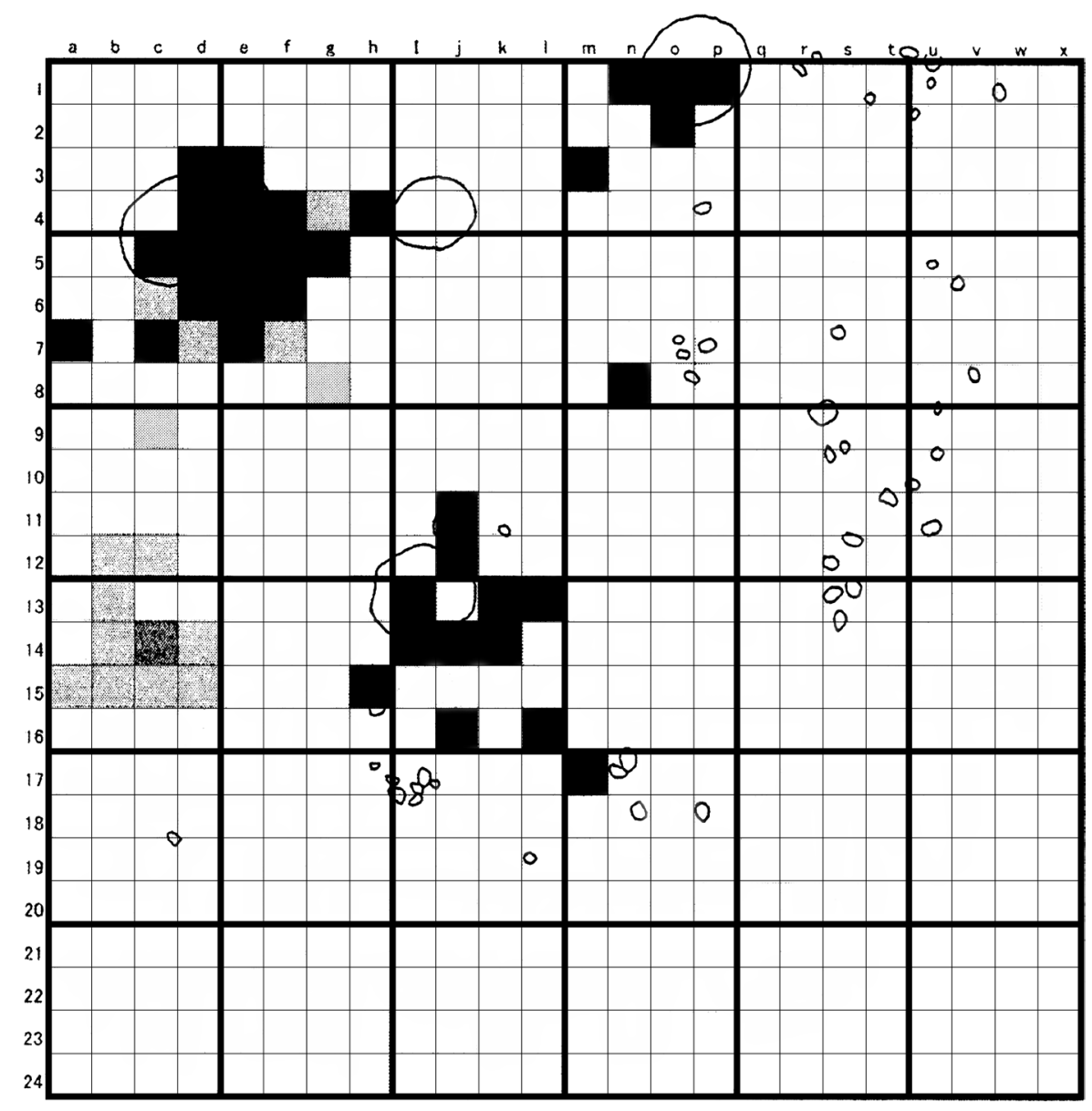

Fig. 7. Macrodebitage scatter and its distribution of thermally altered obsidian (Sakashita 2008: Fig. 9).

Kanto and Hokkaido) as a function of variation in residential activities of Palaeolithic groups under different biogeographic backgrounds. To explore these ideas further, it is necessary to conduct future research focused on quantitative comparisons of data sets among assemblages in different regions to support experimental studies.

\section{Interpretations of the Dwelling Structure}

As we have seen, the analysis of thermally altered obsidian artifacts recovered from the Tana-Mukaihara site revealed that they are only found within the pebble-surrounded structure (i.e., dwelling structure). They are concentrated especially in hearth F2 and postholes P8 and P10. Moreover, thermally altered macrodebitage is not only distributed in hearth F2 and posthole P10, but also in the south of posthole P9.

The tiny cracks observed under the microscope, which are regarded as a reliable trait associated with thermal alteration of obsidian, are generated under the conditions of adherence of wood ash, coupled with certain temperatures and duration of heating, suggesting that thermally altered obsidian artifacts could have been created inside 
hearths. The presence of magnetic signals that were detected on the sediment of hearth F2 supports the idea that the indentified thermally altered obsidian artifacts were created by in situ burning in hearth F2. If this spatial relationship between concentrations of thermally altered obsidian debitage and the location of hearths is confirmed in the study site, the concentrations of the thermally altered obsidian artifacts around postholes P8 and P10 indicate that those features were actually hearths; posthole P10, especially, contains thermally altered macrodebitage, similar to hearth F2.

Furthermore, since the distribution of macrodebitage legitimately indicates locations of stone knapping areas, locations in the southeast of the dwelling structure and two locations around hearth F2 and posthole P10 that are consistent with distribution of the thermally altered obsidian artifacts, indicate that these two areas were the locations of hearths. In contrast, the southern side of the dwelling structure does not encompass thermally altered obsidian artifacts that were recovered in the first and second excavations, making it plausible that no fires were made when the obsidian debitage was left (Fig. 8).

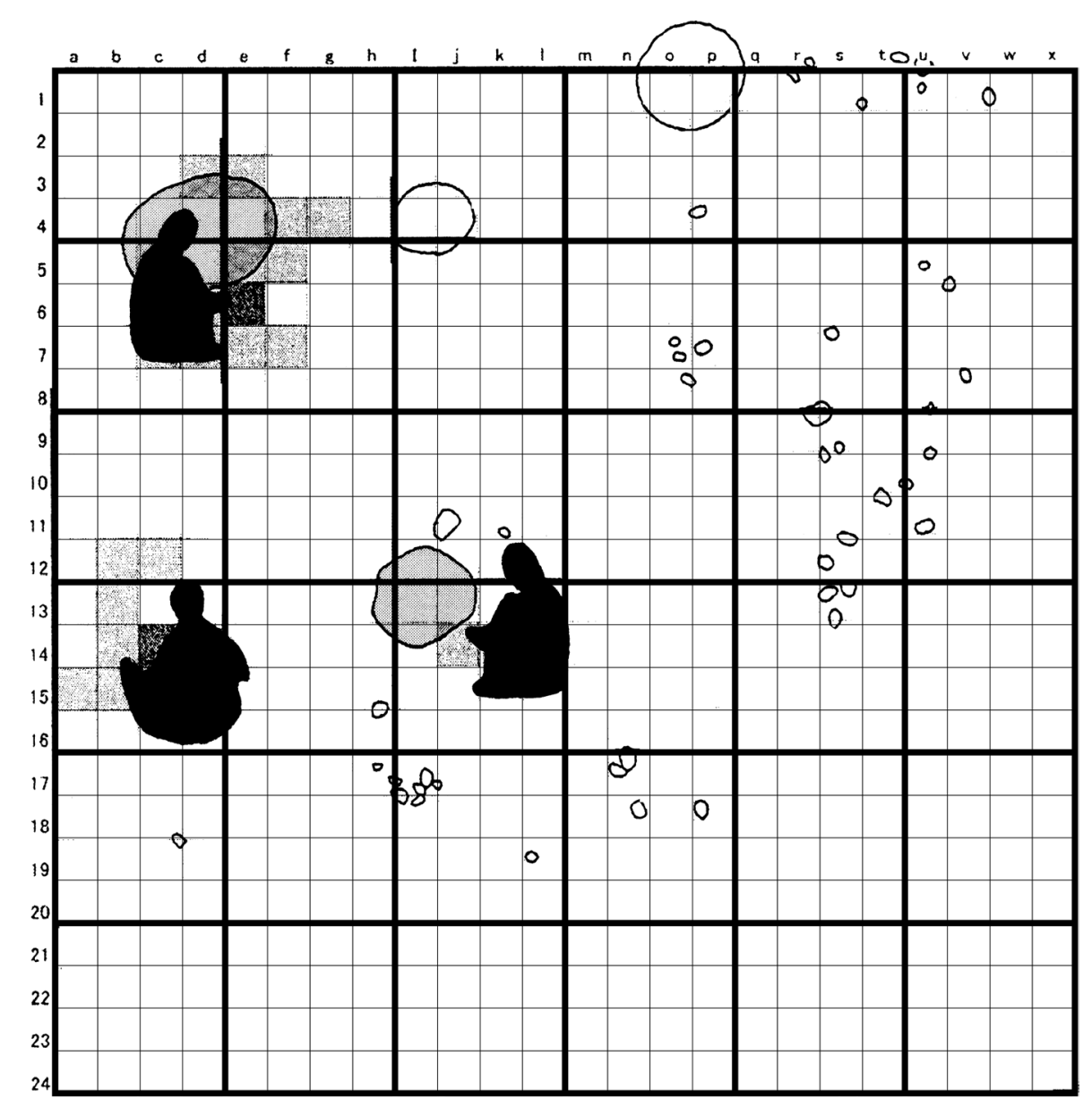

Fig. 8. New interpretation of the dwelling structure (Sakashita 2008: Fig. 10). 
Despite the likelihood that the new inference has explanatory basis, the circularly arranged pebbles that were previously interpreted as a dwelling structure is not completely rejected. Nevertheless, the significant results of the present analysis provide an alternative interpretation: posthole P10 could have been a hearth, and therefore the entrance supposed to have been located between postholes P1 and P10 is illusive. The remaining questions of why the thermally altered obsidian artifacts are sparsely scattered across the entire excavated area and why there is a small concentration of macrodebitage at the southern side of posthole P9 are yet to be answered. To address these questions further, it is necessary to examine additional data from artifacts potentially buried below the dwelling structure; further excavation was suspended for the purpose of cultural resource preservation at the time when the pebble-surrounded structure was unearthed.

\section{CONCLUSIONS}

In this article, I propose a new interpretation of the site structure of the TanaMukaihara site, specifically with regard to the validity of the dwelling structure, through the detailed examination of thermally altered obsidian artifacts. These consisted of four percent of the all artifacts from the first excavation, and most of them are concentrated in association with the hearth within the dwelling structure and with what had been identified as several postholes. Since experiments show that thermal alterations that are visible on the obsidian are created under conditions of attachment with heated wood ash, the spatial distributions of thermally altered obsidian in the site could represent hearth locations. Because the thermally altered obsidian artifacts are concentrated in several alleged postholes, it is likely that these features actually functioned as hearths. This interpretation is legitimized by the fact that spatial distributions of macrodebitage reveal similar patterning. Given the assumption that the locations of macrodebitage correspond with locations of stone knapping activities, and that there were several hearths inside the southeastern areas of the dwelling structure, the manufacture of chipped stone tools was likely conducted around the hearths.

The results of the present article showed that multiple hearths were present within the study site, which in turn provides crucial insight into the problems of identifying dwelling structures in Palaeolithic sites. The rich Upper Palaeolithic archaeological records in the southern Kanto region that encompasses the Sagamino Upland have yielded meticulous chronological studies, which reliably allow archaeological scholars to discuss inter-site relationships and group mobility (M. Suzuki 2005). While the interpretive frameworks of these studies are commonly shared among the majority of Palaeolithic archaeologists in Japan, a critical examination of site structure will lead to new research directions that will elucidate site occupational histories and land use.

\section{ACKNOWLEDGMENTS}

I am grateful to Yuichi Nakazawa for inviting me to contribute this article and for several kind arrangements. Thanks are also due to Akira Ono, Jun Takakura, Sachiko Okazawa, and Katsunori Takase for their helpful suggestions. I am also indebted to Masato Kawamoto and Toshiyuki Tamura, for giving access to the collections from the educational boards of Sagamihara (southern Kanto) and Chitose (Hokkaido) city. 


\section{REFERENCES CITED}

Aita, Yoshiniro

1992 Dwelling structures in the Paleolithic period. The Archaeological Journal 351:2-7 (in Japanese).

Akazawa, Takeru, Shizuo Oda, and Ichiro Yamanaka

1980 The Japanese Palaeolithic: A Techno-typological Study. Tokyo: Rippu Shobo.

Aso, JyunJI

2003 Features and artifacts from the site, in Tana-Mukaihara Site I: 11-85, ed. The Educational Board of Sagamihara City (in Japanese).

BINFORD, LEWIS R.

1978 Dimensional analysis of behavior and site structure: Learning from an Eskimo hunting stand. American Antiquity 43:330-361.

Bowers, Peter M., Robson Bonnichsen, and David M. Hoch

1983 Flake dispersal experiments: Noncultural transformation of the archaeological record. American Antiquity 48:553-572.

The Educational Board of Sagamihara City

2003 Tana-Mukaihara Site I. Sagamihira City: The Educational Board (in Japanese).

2004 Tana-Mukaihara Site II. Sagamihira City: The Educational Board (in Japanese).

2006 Tana-Mukaihara Site III. Sagamihira City: The Educational Board (in Japanese).

Fukuoka, Takashi, and Satoshi Koshimizu

1990 The effect of annealing behavior in obsidian. Journal of the Archaeological Society of Hokkaido 26:53-56 (in Japanese with English abstract).

IMAMURA, KeIJI

1996 Prehistoric Japan: New Perspectives on Insular East Asia. Honolulu: University of Hawai’i Press.

INADA, TAKASHI

2004 Critical studies on the "Palaeolithic dwellings" in Japan. Quarterly of Archaeological Studies 50-3 : 85-101 (in Japanese with English abstract).

KATO, SHINPEI

1970 Historical and regional properties in the Preceramic age, in The Studies of Regional History and Archaeology: 58-92, ed. T. Furushima, T. Wakamori and M. Kimura. Tokyo: Asakura Shoten (in Japanese).

Kato, Shinpei, Hiroaki Hata, and Toshiaki Tsurumaru

1970 On the end-scrapers. Journal of the Archaeological Society of Nippon 55-3:44-74 (in Japanese).

Koshimizu, Satoshi, and Takashi Fukuoka

1991 Thermal effects on the obsidian surface luster loss. Archaeology and Natural Science 24:63-68 (in Japanese with English abstract).

KURISHIMA, YoSHIAKI

1989 Dwelling structures and lithic scatters in the Paleolithic period. Doyou-Kouko 14:21-63 (in Japanese).

Metcalfe, Duncan, and Kathleen M. Heath

1990 Microrefuse and site structure: The hearths and floors of the heartbreak hotel. American Antiquity $55: 781-796$.

Mizoguchi, KoJI

2002 An Archaeological History of Japan, 30,000 B.C. to A.D. 700. Philadelphia: University of Pennsylvania Press.

NaKazawa, Yuichi

2000 Experimental study for detecting morphological effects of thermal alteration on obsidian artifacts and quantitative examination in an obsidian assemblage. The Quaternary Research 39-6:535-546 (in Japanese with English abstract).

2002 An experimental examination for detecting thermal traits on obsidian artifacts, in The Effects of Fire and Heat on Obsidian: 203-219, ed. J. M. Loyd, T. M. Origer and D. A. Fredrickson. US DOI, Bureau of Land Management: Cultural Resources Publication, Anthropology-Fire History.

O’CONNELl, James F.

1987 Alyawara site structure and its archaeological implications. American Antiquity 52:74-108. 
Okazawa, Sachiko

2004 Spatial distribution of macrodebitage, in Tana-Mukaihara Site II: 101-107, ed. The Educational Board of Sagamihara City (in Japanese).

ONO, AKIRA

2004 Summary on dwelling structure, in Tana-Mukaihara Site II: 149, ed. The Educational Board of Sagamihara City (in Japanese).

Ono, Akira, Hiroyuki Sato, Takashi Tsutsumi, and Yuichiro Kudo

2002 Radiocarbon dates and archaeology of the late Pleistocene in the Japanese Islands. Radiocarbon 44-2: 477-494.

SAKASHITA, TAKANORI

2007 Spatial analysis of a Palaeolithic site in Japan: A view from the thermal alteration on obsidian. in The Ethnohistory and Archaeology of Northern Eurasia: Theory, Methods and Practice: 457-459, ed. A. Kharinskii. Irkutsk: Irkutsk State Technical University.

2008 New interpretation of Tana-Mukaihara Palaeolithic dwelling site based on thermal alteration of obsidian. Palaeolithic Research 4:143-153 (in Japanese with English abstract).

SHIRAISHI, Hiroyuki

2004 Tana-Mukaihara site in the Tana-Shioda sites, in Tana-Mukaihara Site II: 230-231, ed. The Educational Board of Sagamihara City (in Japanese).

Suzuki, Cyuji

1983 Human dwellings and settlement in the Paleolithic period. Quarterly Journal of Archaeology $4: 37-42$ (in Japanese).

Suzuki, Miно

2005 Settlement-subsistence system of prehistoric hunter-gatherers: A case from Upper Paleolithic foragers in the Japanese Islands, in The Archaeology of Hunter-Gatherer Societies: 33-49, ed. H. Sato. Tokyo: Asakura Shoten (in Japanese).

The Tana-Shioda Sites Excavation Group

1998 Investigation of the Tana-Mukaihara Site in Sagamihara City. Sagamihara City: The Educational Board of Sagamihara City (in Japanese with English abstract).

Tsuji, Seirchiro, Hiroshi Machida, Sumiko Kubo, and Hiroomi Tsumura

2004 Chronology and environment in the Tana-Mukaihara site, in Tana-Mukaihara Site II: 97, ed. The Educational Board of Sagamihara City (in Japanese).

YAJima, Kunio, ED.

2004 Recent Paleolithic Studies in Japan: Proceedings for Tainted Evidence and Restoration of Confidence in the Pleistocene Archaeology of the Japanese Archipelago. Tokyo: The Japanese Archaeological Association.

\section{ABSTRACT}

The Tana-Mukaihara site is located on the left bank of the Sagami River in the Sagamino Upland in southern Kanto Plain (Honshu, Japan). In addition to the two lithic scatters (mainly composed of obsidian debitage and tools) and two pebble clusters, the site has been recognized as a prominent Upper Palaeolithic site (c. 20,000 CAL.Y.B.P.) because of an exceptional pebble-surrounded habitation area identified as a dwelling structure, 12 postholes, and two hearths. The purpose of this article is to examine human activities in this Palaeolithic dwelling site through the analysis of thermally altered obsidian artifacts and their spatial distributions. The results show that thermally altered obsidian artifacts are not only concentrated around the hearths, but also in the postholes, suggesting that the so-called postholes indeed functioned as hearths with the other two hearths. This study provides new insight into the reality of Palaeolithic dwelling structures in the Japanese Islands. KEYwords: Upper Palaeolithic, spatial analysis, experimental archaeology, obsidian, hearths, macrodebitage. 